\title{
9 Perceptions and Implications of User Participation and Engagement in Libraries, Archives and Museums
}

\section{Introduction}

Engagement with the citizenry is at the heart of the mission of all public institutions. Libraries, archives and museums (LAM) are no exception. What tends to be more difficult to articulate is what this engagement means in practice for LAM institutions and individual organizations. Similarly, there is hardly a consensus of what effect the engagements should have on the public - and even more so, what effect the outcomes should have on the institutions. This chapter inquires into this latter, relatively under-researched question of expectations, experiences and perceptions of the implications engaging with the public has on libraries, archives and museums in Scandinavia.

Users' motivation for contributing to cultural collections have been studied from various angles (e.g. Bonacchi et al. 2019; Roued-Cunliffe and Copeland 2016). This chapter takes a different approach. We will examine the motivations, attitudes, preparedness and willingness to make use of the users' contributions in LAM organizations, a topic that has been studied so far to a considerably smaller extent (Jansson 2017, 2018). Motivations and attitudes involve perceived effects of user contributions on enhancing the public sphere, and possibly a stance on the need for, or the possibilities for, a reorientation of curatorship for digital materials. On a more practical level, integrating user contributions into the official, professional knowledge base, such as the main catalogues of LAM organizations, raises possible concerns about quality, ownership and professional mastery (Oomen and Arroyo 2011). Our research is based on a survey exploring both attitudes and the editing policies implemented in tools that are made available for users.

When users are invited to share their knowledge, experiences or affections related to cultural heritage disseminated by LAM organizations, the context of the participatory endeavor is sometimes organized as a project of limited time and scope, and sometimes as a standing invitation to contribute knowledge to the collection catalogue. While promoting participation and engagement often is the stated, primary purpose for inviting user participation, the arrangements and the technical solutions are often merely designed for enhancing catalogue metadata 
pertaining to specific objects in a collection. The function of enhancing metadata could, as Eveleigh (2014) notes, be poorly served by conceptualizations of user participation and engagement.

However, for this study, we were interested in the durability of the contributions that users make to LAM organizations' catalogues. Instead of focusing on what the user may get out of his or her participation, we wanted to look into what the organizations do with the pieces of knowledge users have provided. This is a question consisting of two broad elements. The first main element is about attitudes and perspectives on the role of the users. Are the users' knowledge about collection objects something LAM organizations need, or even want, to be part of the enduring catalogue information? Will user contributions be perceived as a different form of knowledge, subject to other standards of quality and relevance than the professionally maintained catalogue information, or should they be held to the same standards and therefore be closely reviewed by LAM professionals? The second broad question is about practices in existing arrangements and systems for gathering user contributions. The rationale of examining practices is to learn whether user contributions are actually integrated into the main catalogues of the LAM organizations. To this aim, the survey questions on practices covered what kind of contributions the currently used technical systems are supporting, who are allowed to edit contributions and on what conditions, what the storage policies look like, and whether the organizations are performing regular assessments concerning the quality of the user assessments.

Integrating additional information into the catalogues is by no means the only possible benefit from user contributions, but there are two reasons why it is worth examining. The first one is that many existing tools and arrangements are designed in a way that convey an impression of contributing to permanent and accumulating knowledge. The second one is that catalogues, despite several differences, form a common ground for negotiating and bridging knowledge organization between the different LAM disciplines.

\section{Theoretical Approach}

Wikipedia has been characterized as a great success of user contributions through digital technology: "The true wonder of wiki-platforms is their capacity to mobilize contributors in great numbers and to incite them to write and edit articles" (Henningsen and Larsen, in this volume). LAM organizations may also profit in many ways from the potential of engaging the populace at large in contributing to their work, but widely different institutional contexts and traditions of how professionals and the public are expected to collaborate mean that LAMs cannot 
simply reproduce the success of the most eminent wiki-based collaborations, although the local history wiki under the administration of the National Library of Norway has been quite successful.

There are several competing lines of discourse focused on explicating how the very nature of scientific or cultural knowledge may be affected by user engagement. One influential strand of discussion perceives transition from hegemonial discipline-oriented scientific discoveries to more application-oriented scientific knowledge production involving larger parts of society (Nowotny, Scott and Gibbons 2001). Another approach, more narrowly applicable to cultural heritage, is the paired concepts of "heritage" and "voice" which are different rationales for using and sharing cultural heritage knowledge (Ivey 2009). As our study does not aim to explore such qualitative features of different forms of knowledge per se, they are not going to be discussed here in detail, but we assume that underlying discourses on what makes knowledge trustworthy, relevant and adequately organized will form a backdrop to the respondents' answers to the survey questions.

Ridge (2014) takes as a starting point that crowdsourcing has become increasingly popular in memory institutions as a tool for digitizing or computing vast amounts of data. Nevertheless, there are signs that indicate a certain restraint among the LAM institutions. Huvila (2015) has analyzed how "participation" is discussed in the context of archives and records management and explored practical and theoretical implications of the disclosed discursive practices. He found that there was not one notion of participation, but nine different and partly conflicting types of participation. Further, he notes that there is fairly little research on how participation is conceptualized by archives professionals and researchers.

There might be a mismatch between the values and missions of the LAM institutions and the idea of crowdsourcing. Owens has pointed at the definition of crowdsourcing, especially in terms of "outsourcing" (Owens 2014), and contributed to opening up and redefining the concept: "What crowdsourcing does (and most digital collection platforms fail to do) is to offer an opportunity for someone to do something more than consume information." (278).

Eveleigh (2014) has pointed out that crowdsourcing also harbors a hidden threat to professionalism:

Crowdsourcing initiatives in archives, as in related professional fields, are also haunted and constrained by the fear that a contributor might be wrong, or that descriptive data might be pulled out of archival context, and that researchers using collaboratively authored resources might somehow swallow all of this without question or substantiation (2015)

But this threat might also lead to a new concept of profession within the institutions that opens up for user participation. Phillips argues that a new model of 
"open authority" is required to combine effectively community contributions and museum expertise in interpreting shared heritage (Phillips 2014, 247). This also means a new role of the curator:

Stemming from this need for additional curation, the traditional role of the curator as a content provider should be augmented with that of a platform provider, gathering and dispersing information in addition to creating it.

User participation may be regarded as a means of democratizing the cultural heritage. Nevertheless, Bonacchi et al. (2019) found that crowdsourcing cannot straightforwardly be considered a democratizing form of cultural participation. The involved public cohort is not radically different in socio-demographic makeup to the one that physically visits such institutions, being for example financially better-off with high levels of formal education.

Crowdsourcing has also been proposed as an approach for promoting the convergence of LAMs (Kalfatovic et al. 2008). The LAM sector is seen as a whole, but there are obvious differences between the institutions. Theimer (2015) explores how archivists and special collections librarians in organizations of different sizes and types have approached the challenges of collection, as well as exploring opportunities to acquire new kinds of materials and conduct thoughtful reappraisal.

Another line of research has focused more generally in professional attitudes and expectations in the LAM context. Huvila $(2012,2014,2016)$ has surveyed LAM professionals' views of the future of their institutions. Similarly to participation, he found that the attitudes differ considerably even if it is possible to identify certain broad views or subject positions that can be identified across the field. In the two studies, the professionals were in favor of the idea of LAMs as promoters of civic engagement and user involvement as a key facet of how LAMs should work in the future. At the same time, it was apparent that the expectations of how LAMs should work and what they should achieve were not entirely compatible with each other, and there was a lack of clarity and even theoretical depth in the views that could be seen as a hindrance to formulating a clear "positive orthodoxy" (i.e. vision) of what LAMs should do or be in the future. As Marty (2012) underlines, there is a need to be more open towards users as contributors but also of articulating the role and contribution of professional staff.

\section{Methods and Material}

Our approach to the question of what are the implications of user participation for the LAM institutions is to investigate both attitudes and practices of LAM professionals. The combination of attitudes and practices was thought to provide 
an insight into a possible tension between professional custodians' authoritative knowledge and the perhaps more digressive and harder-to-verify contributions made by users. Attitudes and opinions related to their own field of work is something we would expect from any LAM professional, as acquired norms and values are part of what defines a profession (Wilensky 1964).

The data was collected using an online survey submitted to LAM professionals in three Scandinavian countries (Norway, Sweden and Denmark) in 2019. The survey questionnaire was developed and both linguistically and culturally translated by an international team of researchers. The survey was managed locally in the participating countries using online survey software available at the participating research institutions.

The design of the survey had all respondents $(\mathrm{N}=2443)$ answering the questions on attitudes towards crowdsourcing, regardless of whether they had any experiences with such solutions or not. Only respondents with either current or previous experiences with crowdsourcing solutions were asked the questions pertaining to practices. The number of respondents who had experiences with such solutions was 258 out of 2443 . Unfortunately, due to a misconfiguration of the survey forms sent to the Danish respondents, the questions pertaining to practices were missing. Therefore, the 90 Danish respondents out of those 258 respondents who had experiences with crowdsourcing solutions did not get the opportunity to answer questions about practices. Hence, only Norwegian and Swedish respondents $(\mathrm{N}=168)$ were asked these questions.

The questions regarding practices was also directed at LAM professionals, which proved to be a bit of a stretch, because the affordances offered by technical solutions for user contributions result from the institutions' policies and not from individual professional judgment. Hence, more precisely, the survey data on practices tell us about the LAM professionals' knowledge of their institutions' policies and practices. As our respondents are professionals in LAM organizations, it should be noted that it is their individual experiences and knowledge about their organizations' handling of user contribution that is surveyed. The organizations may have policies and mechanisms in place that our respondents are not aware of. Gaps in the knowledge of institutional policies is expressed by a fairly high number of "I don't know" answers in this part of the survey.

As mentioned above, the questions on experiences and policies were not included in the surveys answered by Danish archives or museums professionals. Therefore, this part of the survey only includes data from Norway and Sweden. This makes a total of six different survey forms, to archivists, librarians and museologists respectively, in both countries. The questions were essentially the same, though in different languages. The tools and methods for collecting data have also been slightly different. Unfortunately, this has led to two minor issues with a vari- 
able containing information on what forms of user contributions has the organization made arrangements or technical solutions for. This question has eight options, with the possibility of selecting more than one. The survey sent to Norwegian librarians missed the first option, "Adding predefined keywords or classification data", and the survey sent to Swedish museologists only allowed for one selection for each respondent on this question, thus perhaps missing out some forms of user contributions they actually have on offer.

Respondents were recruited using measures that were deemed appropriate in order to reach as many LAM professionals in each country as possible. The nonavailability of comprehensive lists of all LAM professionals in the participating countries restricted both the possibility to include complete populations in the survey and the possibility to make systematic assessment of the representativity of the samples. The measures included the use of professional mailing lists, websites, social networks and contacting national professionals associations. As a result, the data represents a convenience sample. In spite of the shortcomings of the survey approach and the presence of an unknown bias, the data is still useful for the exploratory rather than confirmatory aims of the present study.

\section{Analysis}

The data was analyzed with SPSS 25.0 using descriptive statistics and one-way analysis of variation (ANOVA).

\section{Attitudes}

The attitudes were analyzed using a set of 20 questions on an 11-point Likert-like scale. The questions listed in Table 9.1 were adapted to fit the vocabulary and conditions respectively in libraries, archives and museums and translated to Norwegian, Swedish and Danish for the survey.

\section{Country and Profession Related Variation}

The findings show that the attitudes towards user contributions and contributing in the Scandinavian LAMs have a lot of similarities in spite of some country and profession-specific variation. Profession-wise the attitudes differed in all other questions (on significance level $\mathrm{p}<0.001$ ) than $(\mathrm{e})$, a major reason for engaging people to participate in the work of LAM institutions is to get more visitors and users to the institutions. Country-wise the attitudes differed in all other cases 
Tab. 9.1: Questions on the attitudes towards user contributions

a It is very important to engage the public to work together with professionals in [libraries/archives/museums]

b The public can enrich [libraries/archives/museums] collections by providing additional information

c Engaging the public as volunteers helps [libraries/archives/museums] to deliver high quality services with smaller financial resources

d Engaging the public reduces the number of professional staff needed in [libraries/archives/museums]

e A major reason for engaging people to participate in the work of [libraries/archives/museums] is to get more visitors and users to the institutions

f Managing [libraries/archives/museums] collections in the future is impossible without contributions made by the public

g The high number of passive, non-contributing members of the public is a problem, we should expect more from our users

$\mathrm{h}$ Engaging users as contributors provides important support for the public discourse in the society

i Engaging users as contributors is a democratic responsibility of [libraries/archives/museums]

j Letting the members of the public contribute is a form of listening to them and giving them an opportunity to experience benefits of [libraries/archives/museums] from their own premises

$k \quad$ A major reason for engaging people to participate in the work of [libraries/archives/museums] is to empower them as individuals

I Many users are more knowledgeable of the collections than [libraries/archives/museums] professionals, both as subject experts and as the users of the collections

$\mathrm{m} \quad$ User engagement at [libraries/archives/museums] should be a user-driven activity (i.e. decisions should be made by users)

$\mathrm{n} \quad$ User engagement at [libraries/archives/museums] should be marshalled by professionals

o Additional information supplied by users should be re-examined by professionals

p The most important contributors are earlier owners or stakeholders of collection items

$q$ The members of the public who are contributing should be treated as equals to the professionals

$r \quad$ New digital technologies allow [libraries/archives/museums] to engage users in the management of collections

s A significant aspect of participation is to engage users within their own fields of interest, or in ways that are relevant to their own life situations

$\mathrm{t}$ Engaging the public to contribute is how [libraries/archives/museums] should work with their users today 
than (d), engaging the public reduces the number of professional staff needed in LAM institutions, and ( $n$ ), user engagement at LAM institutions should be marshalled by professionals.

The attitudes were most split regarding the questions of whether (p) the most important contributors are earlier owners or stakeholders of collection items (e.g. books, records, objects) (mean 3.47, SD 3.267). Here especially Swedish archivists (mean 7.15) and museum professionals (mean 6.48) considered it helpful whereas Danish (mean 0.00) and Norwegian (mean 2.22) librarians and Danish museum professionals (mean 2.47) thought the contrary.

Also the question whether (c) engaging the public as volunteers helps LAM institutions deliver high quality services with smaller financial resources (mean 5.10, SD 3.258) divided opinions. The Danish librarians were the most negative whereas many others, especially Danish (mean 6.96) and Norwegian (mean 6.28) archivists and Norwegian (mean 6.45) and Swedish (mean 6.55) museum professionals, were positive.

With regards to the issue of whether the (r) new digital technologies allow LAM institutions to engage users in the management of collections (mean 3.60, SD 3.189), the museum professionals (mean 5.68) and archivists (mean 5.15) were fairly optimistic whereas library (mean 2.68) professionals were pessimistic. They were also less inclined to believe (mean 3.13), together with Danish museum professionals (mean 3.15), that (l) many users are more knowledgeable of the collections than LAM professionals, both as subject experts and as the users of the collections - another issue with divergent views among the respondents (mean 3.79, SD 3.116),

Regarding the question of whether (i) engaging users as contributors is a democratic responsibility of LAM institutions (mean 5.24, SD 3.114), the Swedish (mean 5.90) respondents were more positive than the others, especially the Danes (mean 4.29). Considering if ( $\mathrm{k}$ ) a major reason for engaging people to participate in the work of LAM institutions is to empower them as individuals (mean 4.91, SD 3.114), the respondents in Denmark and Norway, especially in archives (DK mean 3.33; NO mean 3.02) and museums (DK mean 3.55; NO mean 3.99), agreed less with the statements than Swedes (mean 5.65).

The respondents showed least variation in their views that (d) engaging the public reduces the number of professional staff needed in LAM institutions (mean 1.39, SD 2.161), and that (m) user engagement at LAM institutions should be a userdriven activity (i.e. decisions should be made by users) (mean 2.64, SD 2.479).

As a whole, the respondents were inclined to consider that (o) additional information supplied by users should be re-examined by professionals (mean 7.35, SD 2.871) and (n) user engagement at LAM institutions should be marshalled by professionals (mean 6.93, SD 2.912), but that (b) the public can enrich collections 
by providing additional information (such as reviews, recommendations or supplementing catalogue data) on collection items (mean 6.72, SD 2.790) and (j) letting the members of the public contribute is a form of listening to them and giving them an opportunity to experience benefit of LAM institutions (mean 6,60, SD 2.838).

The respondents were least inclined to believe that (d) engaging the public reduces the number of professional staff needed in LAM institutions (mean 1.39, SD 2.161), (g) the high number of passive, non-contributing members of the public is a problem, we should expect more from our users (mean 2.44, SD 2.474), (f) managing collections in the future is impossible without contributions made by the public (mean 2.47, SD 2.719), and (m) user engagement at LAM institutions should be a user-driven activity (i.e. decisions should be made by users) (mean 2.64, SD 2.479).

\section{Demographic Differences}

The role of demographic factors in explaining the differences in attitudes was studied using one-way analysis of variation (ANOVA). According to the findings (at the significance level <.001), the male respondents were more inclined than females to consider that (d) engaging the public reduces the number of professional staff needed in LAM institutions $(F(3,2435)=11.462$, $p<.001)$, (f) managing collections in the future is impossible without contributions made by the public $(\mathrm{F}(3,2421)=7.511, \mathrm{p}<.001)$, $(\mathrm{g})$ the high number of passive, non-contributing members of the public is a problem, we should expect more from our users $(F(3,2422)=$ 6.870, $\mathrm{p}<.001),(\mathrm{m})$ user engagement at LAM institutions should be a user-driven activity $(\mathrm{F}(3,2404)=6.355, \mathrm{p}<.001)$, $(\mathrm{p})$ the most important contributors are earlier owners or stakeholders of collection items $(\mathrm{F}(3,2399)=12.510, \mathrm{p}<.001)$, and (r) new digital technologies allow LAM institutions to engage users in the management of collections $(F(3,2398)=20.344, p<.001)$. In contrast to these fairly instrumental questions, females scored slightly higher in questions about outreach $(e, j)$, public discourse $(h)$ and empowerment $(k)$ even if none of these differences were statistically significant.

Education is also a factor that is linked to attitudinal differences. The LAM educated were generally less enthusiastic about user contributions than others in all questions other than (k), a major reason for engaging people to participate in the work of LAM institutions is to empower them as individuals, even if this particular difference was not statistically significant. The differences are significant for questions a, b, c, d, f, g, l, m, p, q, r, and t, and non-significant for e, h, i, j, $\mathrm{k}, \mathrm{n}, \mathrm{o}$, and s. A comparison of the differences gives an impression that the LAM educated respondents were more concerned of LAMs as an actor and institutional 
implications of participation, whereas non-LAM educated focused more on users as an active primary stakeholders in the equation.

\section{Practices}

\section{Experiences With and Knowledge Of Policies and Mechanisms}

As a starting point for analyzing practices, we asked whether the organization where the respondent is employed has had any experience with digital tools for user contributions. Only respondents answering "yes" on either of the two first alternatives ("such solutions are currently in use" or "such solutions have been tested earlier") were asked to answer the remaining questions on the practical handling of the user contributions within the organizations. Table 9.2 shows distributions by country of respondents who did or did not have any experience with such solutions in their own organization.

Tab. 9.2: Have you, or the LAM organization you work for, ever planned or used a technical solution for "crowdsourcing", where external users of digital collections may contribute to the collections or the catalogue data by providing additional information?

\begin{tabular}{|c|c|c|c|c|}
\hline & \multicolumn{3}{|l|}{ Country } & \multirow[t]{2}{*}{ Total } \\
\hline & Denmark & Norway & Sweden & \\
\hline \multirow{2}{*}{$\begin{array}{l}\text { Yes, one or more such technical } \\
\text { solutions are currently in use }\end{array}$} & 67 & 74 & 61 & 202 \\
\hline & $2.7 \%$ & $3.0 \%$ & $2.5 \%$ & $8.3 \%$ \\
\hline \multirow{2}{*}{$\begin{array}{l}\text { Yes, we have tested that kind of } \\
\text { technical solution, but we are not } \\
\text { currently using it }\end{array}$} & 237 & 147 & 197 & 567 \\
\hline & $0.9 \%$ & $0.6 \%$ & $0.8 \%$ & $2.3 \%$ \\
\hline \multirow{2}{*}{$\begin{array}{l}\text { No, but I know that my organization } \\
\text { is planning or considering that kind } \\
\text { of technical solution }\end{array}$} & 347 & 487 & 367 & 1187 \\
\hline & $1.4 \%$ & $2.0 \%$ & $1.5 \%$ & $4.8 \%$ \\
\hline \multirow{2}{*}{$\begin{array}{l}\text { No, and neither am I aware that any } \\
\text { such technical solution has been } \\
\text { considered }\end{array}$} & 3527 & 3337 & 6547 & 13397 \\
\hline & $14.4 \%$ & $13.6 \%$ & $26.8 \%$ & $54.8 \%$ \\
\hline \multirow[t]{2}{*}{ I don't know } & 2417 & 1357 & 3527 & 7287 \\
\hline & $9.9 \%$ & $5.5 \%$ & $14.4 \%$ & $29.8 \%$ \\
\hline Total (Count) & 717 & 604 & 1122 & 2443 \\
\hline Total (Per cents) & $29.3 \%$ & $24.7 \%$ & $45.9 \%$ & $100.0 \%$ \\
\hline
\end{tabular}


Having planned or using a technical solution for crowdsourcing was rare in all countries even if it was more common among Danish and Norwegian respondents than Swedes. 12.3\% (74/604) of Norwegian, 9.3\% (67/717) of Danish and 5.4\% (61/1122) of Swedish respondents indicated that a such solution was planned or in place. 2.3\% (14/604) of Norwegian, 3.2\% (23/717) of Danish and 1.7\% (19/1122) of Swedish respondents indicated that such a solution had been tested. Over half indicated that no crowdsourcing was used, and in what can probably be taken as an indication of the priorities, 33.6\% (241/717) of Danish, 22.4\% (135/604) of Norwegian and 31.4\% (352/1122) of Swedish respondents did not know. A slightly larger group had tested such solutions but were not currently using them.

Of the different functions, $41.1 \%$ had or had planned giving opportunity to add information about persons, families, organizations or places represented in the collection objects, $15.6 \%$ adding keywords or classification data, $60.5 \%$ adding free text descriptions or comments, 32.4\% providing transcriptions, $37.4 \%$ correcting errors or disputable existing information and $8.6 \%$ establishing links between objects in the collection, while almost one fourth, $23.8 \%$, indicated that they did not know.

Approximately half of the respondents indicated that the users of their crowdsourcing services belong to either organized groups, or that they have a distinct field of interest.

The information users contributed could in most of the cases be edited by authorized persons within the organization (75.6\%). In $16.7 \%$ of cases external users who had entered the information could edit it, while in $7 \%$ of cases anyone could edit it.

In a slight majority of the cases, the crowdsourced information was either planned to be kept by the organization (26.6\%), or no explicit decision had been made (25.3\%). Only in a few cases had a decision actually been made to delete the information after a certain period of time (4.4\%).

The most typical procedure (42.8\%) to manage contributions, indicated by the respondents, was that organizations perform regular assessments of all (or of a significant amount of) the user contributions and incorporate them in the primary catalogues or storage systems. Fairly seldom were the edits incorporated directly (7.5\%). More often they were not incorporated at all (13.8\%).

Only a few respondents (13.1\%) indicated that their organization had conducted systematic evaluations of their crowdsourcing. Thirty-five per cent had not conducted evaluations, nor did they have immediate plans to do so. The results of the evaluations had indicated mixed impacts with most reported cases of positive impact in Sweden and least in Denmark.

The proportion of LAM professionals who reported actual experiences with technical solutions for user contributions were $9.6 \%$ (168 out of 1753 respondents) 
from Norway and Sweden. The proportion of Norwegians with such experiences are $14.5 \%$ (88 out of 605 ), while it was $7 \%$ (80 out of 1148 ) in Sweden. The main explanation for this difference is that the number of librarians responding in Sweden was quite high, while there is a small proportion of librarians who have any experience with solutions for user contributions. This does not imply that user contributions are considered less important in the library sector, but it is probably fair to assume that library professionals are more often employed in small units, and therefore less involved in such activities than archivists and museologists.

Are there any specific categories of professionals who seem to engage more in user contributions? The age group does not seem to play much into it. Out of the respondents who answer that they or their organization have experiences with solutions for user contributions, $8.6 \%$ are 34 years or younger, 9.4\% are between 35 and 49 , and $10.4 \%$ are 50 years or older. These are small differences, though it is interesting to notice a slightly higher proportion with the older age groups.

Whether the professionals work in a public institution or not seems to have a somewhat higher impact. The data on this variable has a lower $\mathrm{N}$ (1382, instead of 1753 as for the rest of the data set), because information on public or private ownership is lacking for the group of Norwegian librarians. The total portion of professionals with experience or knowledge of solutions for user contributions is $11.5 \%$ for this variable, instead of $9.6 \%$ for the rest of the data set. The proportion of these respondents who work in public LAM organizations is $9.3 \%$, while the portion working in a non-public organization is $18 \%$. This difference is consistent with the numbers that show that such solutions are most widespread in museums, as the proportion of museums that are not publicly owned is higher than for archives and libraries.

The type of educations seems to have a higher impact: $7.8 \%$ have some sort of LAM education, while $14.3 \%$ have another university degree or similar. The proportion with no higher education is zero. The difference between LAM educations and other educations comes almost solely from the library sector. While most librarians have an LAM, more specifically a LIS, education, the proportion of people involved with solutions for user contributions are mostly people with other academic backgrounds. If we look at the proportions for museum and archives in isolation $(\mathrm{N}=628)$, the proportion of respondents who have experience with or knowledge of solutions for user contributions is virtually equal for those with an LAM education (22.8\%) and those with another academic education (22.4\%).

The final independent variable to look at is gender. Generally speaking, there is a high proportion of women working in LAM institutions. The overall proportion for the data set is $74.8 \%$ women. Librarians have the highest proportion of women; for archives and museum the proportion of women is $62 \%$. However, dealing with user contributions seems to have appealed to a slightly higher share of 
male employees in the LAM organizations. 7.9\% of the respondents who have experiences with or knowledge of the organizations' solutions for user contributions are women, with $14.6 \%$ of them men. Again, librarians account for some part of the bias, but there is still a gender difference when archives and museums are seen in isolation: $21 \%$ of the women and $24.2 \%$ of the men. This appears to be a small difference, but it is worth noting a difference between Sweden and Norway as well. For archivists and museologists in Norway, $26.2 \%$ of those who deal with user contributions are women, while 33.6\% are men. In Sweden, the difference is smaller, and the proportion of women is slightly higher (17.7\% women, $15 \%$ men). This seems to indicate that working with solutions for crowdsourcing has appealed to men in Norway, while this is not the case in Sweden.

\section{Policies and Mechanisms in LAM User Contribution Arrangements}

The user contributions may be of different forms. This question was open for checking multiple boxes, thus the sum of total percentages is higher than 100 .

As noted earlier, the first out of these columns was left out of the survey form sent to Norwegian librarians, which contributes 8 out of the 168 persons in this data set. This is reflected in the percentages of the first column of Table 9.3. The second problem with this table is that the survey sent to Swedish museologists was missing the possibilities to mark more than one option. In addition to these seven columns, there was also an option for answering "I don't know”, which was only available if not combined with any of the other options. "I don't know" achieved a total of $11.3 \%$ of the answers.

The most prevalent form of user contributions is to add free text descriptions or comments to digital objects in a collection. This functionality is available in the technical solutions that $53.6 \%$ of the professionals had experience with or knowledge of in their own organization. Using predefined keywords or establishing links between objects in a collection were the least popular ones. This could be because these forms may require more professional skills.

\section{The Professionals' Perceptions of Their Users}

The question asked was "what are the most significant characteristics of the external users of the technical solution(s)"? Only one answer to the question was possible, see Table 9.4.

There is somewhat high variance on this question, but some patterns may be interesting. Librarians, both in Norway and Sweden, held the highest rates of the answer "I don't know". More than half of Norwegian archivists perceive their users to belong to an organized group, such as local historians or genealogists. An 

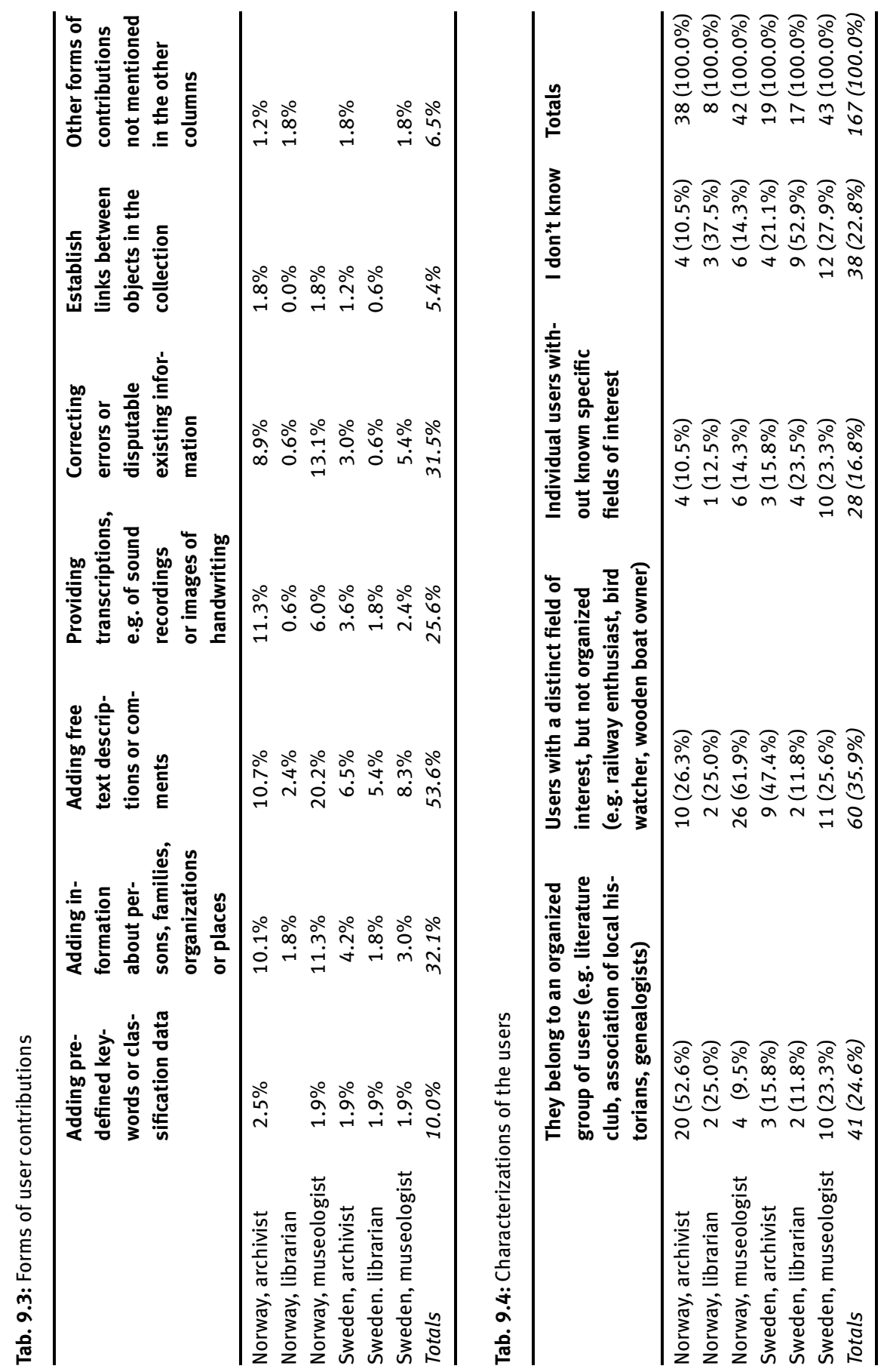
even higher proportion of Norwegian museologist, 61.9\%, perceived their users as persons with a distinct field of interest, but who are not organized.

\section{Editing Policies}

Another question about policies and mechanisms was who may edit the information that users have contributed, see Table 9.5. Again, several options could be selected.

The highest score is for the option "authorized user within my organization". Very few were pursuing policies that external users may edit contributed information themselves. It is worth noting that the option "I don't know" came out with the second highest score, 58.9\%. This probably signifies that the question of authorizations for editing information has not received sufficient attention.

\section{Retention Policies}

We also wanted to look into the questions of what happens to the user contributions after they had been collected, and - possibly - verified or checked for quality by the organization. We asked two questions related to this concern, see Table 9.6.

The first one was "for how long will the organization store information that is contributed by external users"?

This is clearly a matter that has not been settled very well, nor communicated well within the organizations. The last two alternatives, either that no decision has been made or the respondent doesn't know, got more than two thirds of the answers combined. Only a marginal number of respondents indicated there was a policy of deleting user contributions after a certain period of time. Almost one third answered that the organization intended not to delete the user contributions.

\section{Integrating User Contributions in Primary Catalogues}

The second question concerning what would happen to user contributions, see Table 9.7, was "in what way (if any) does the user contribute information incorporated into the organization's primary catalogues or storage systems”?

The answers to this question, we believe, probably indicates a low level of maturity of the policies governing user contributions. Even if user contributions remain within a specific technical solution that the users have access to for a very long time, a defined policy on if, how and when the users' knowledge or suppositions will be necessary for the contributions to survive for a long time, across technology changes and further developments of the collections. As many as $81 \%$ of the Norwegian museologists indicated their policy was to assess the user contributions regularly. This policy seems to be widespread with museologists in Swe- 


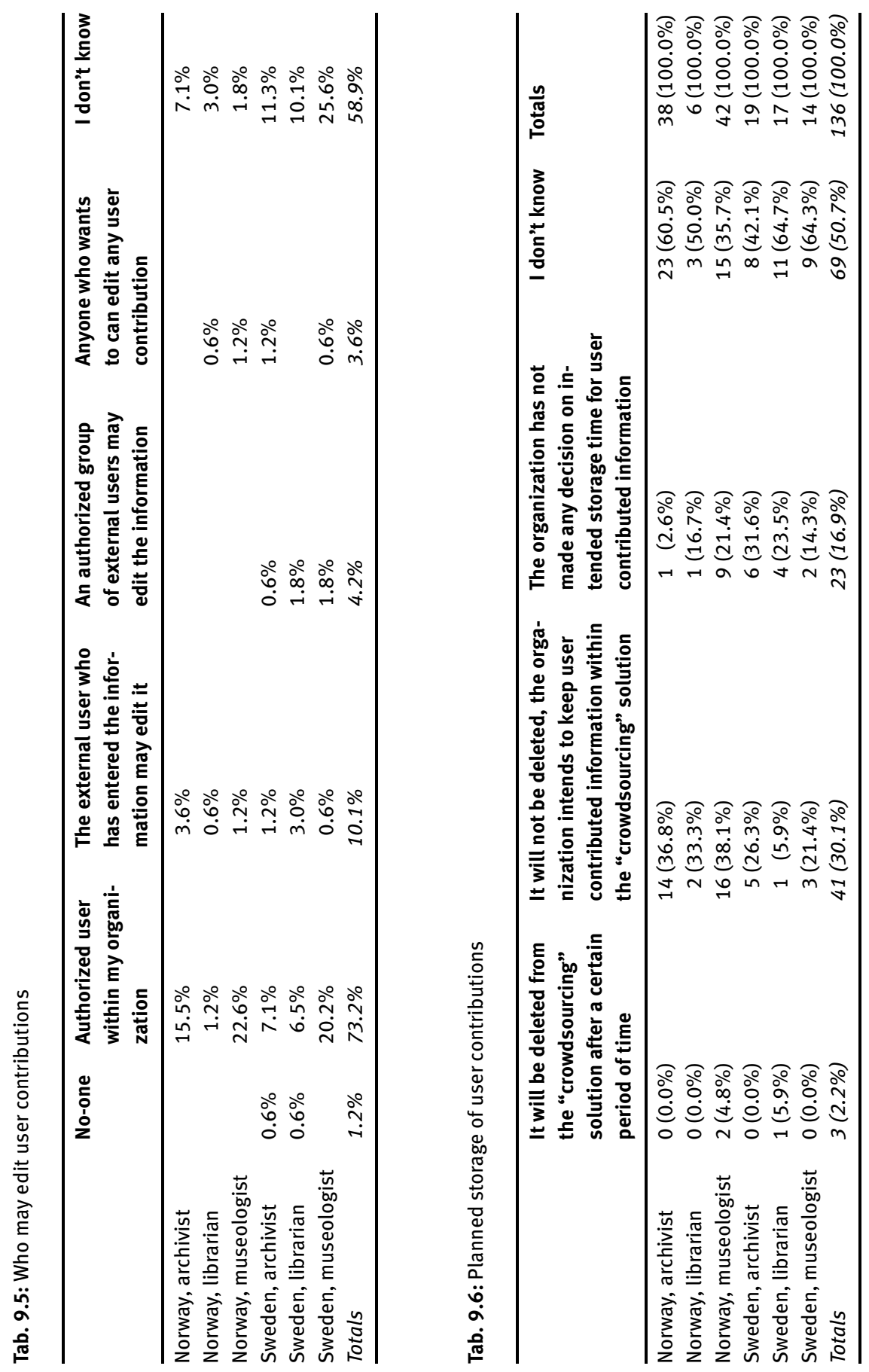




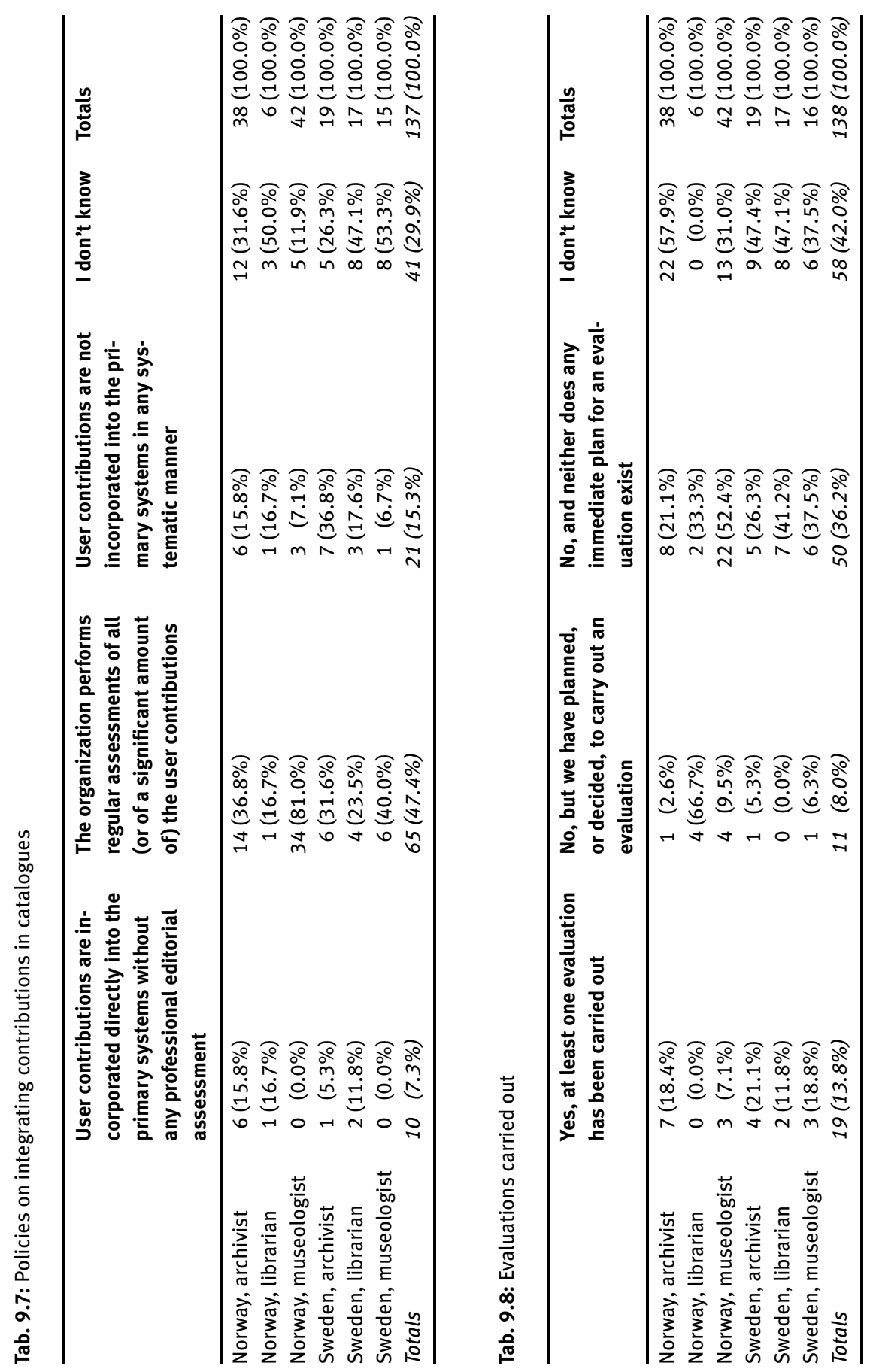


den and with archivists in both countries as well, though the rates are lower. On the other hand, the overall "I don't know"-answers were almost one third (29.9\%) also for this question. There seems to also be a need for clarifying and communicating policies within the organization on this matter.

\section{Whether the Crowdsourcing Solutions Have Been Evaluated}

The last questions in the surveys were on whether there had been evaluations of the solutions for user contributions used by the organizations.

As shown in Table 9.8, only 13.8\% answered that at least one evaluation has been carried out. Another $8 \%$ had either plans or made a decision for carrying out an evaluation. The remaining almost $78.2 \%$ were either "no" or "I don't know". It should probably not be very surprising, as many of these activities and initiatives are fairly new to the organizations. However, the unsettled, or poorly communicated, policies on how the organizations will deal with user contributions indicates that evaluation of such solutions will probably be a good idea.

The last question was on the results from an evaluation, see Table 9.9. As there were low numbers of respondents who knew of any such evaluation, there were also few answers to this question. In those few instances, however, the results were mostly positive.

\section{Discussion}

The analysis showed that there are differences in user contribution related attitudes among the respondents but that they are surprisingly small, whereas the differences in practical experiences are considerable between a small number of respondents who had such experiences, and the large majority who had not engaged users as contributors. In some country-specific attitudinal differences, there could be seen echoes of different emphases in the national LAM policies. For instance, Swedish respondents were more inclined to emphasize the democratic and empowering role of LAMs than their Danish and Norwegian colleagues. It was difficult to see similar patterns in the practical experiences.

Considering the profession-wise differences, it is hardly surprising that museum and archives professionals were somewhat more inclined to think that, for instance, experts or previous owners of collection items could be especially useful contributors. The respondents were in favor of maintaining the curatorial responsibility at the institutions. While the professionals were positive towards engaging users as contributors of additional information and engaging them in a dialogue, they did at the same time not believe that user engagement would re- 


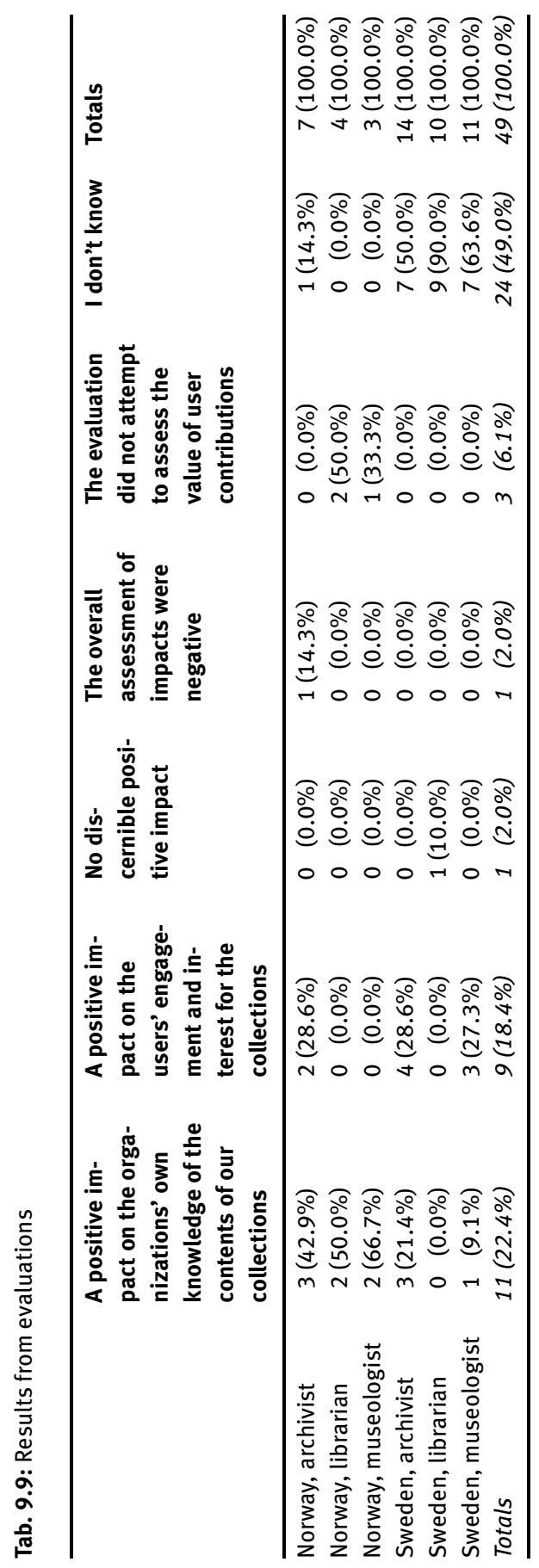


duce the number of professional staff needed in LAM institutions or that the lack of engagement of some users would necessarily be a major issue. This finding confirms earlier, not necessarily unsurprising, observations in the literature that the professionals are not inclined to believe that their role is diminishing. To a certain degree, the findings seem to suggest that the male respondents were more worried about the technical viability of user engagement, such as risks of nonengagement, whereas the female respondents were more focused on the soft (e.g. democracy, empowerment) benefits of working closer with users. The significance of the LAM professions and respondents' identification as a LAM person as a key factor that explains attitudes was visible also in the differences between LAM educated and other respondents. LAM educated individuals underlined the role of LAM professionals whereas the others were more inclined to emphasize the importance of letting users decide.

As a whole, engaging users as contributors is still very rare and in spite of the small number of success stories (e.g. Ridge 2016; Roued-Cunliffe and Copeland 2016), an average LAM professional has little or no experience of engaging users as contributors. For the same reason, the common attitudes towards user contributions are anchored on expectations and how participation has been discussed in the academic and professional literature rather than on first-hand experiences. The lack of first-hand experience on engaging users as contributors is especially striking considering the analyzed data. It would have been plausible to expect that respondents with earlier experiences would be overrepresented in the final sample as they could be assumed to be more interested in answering user contribution related questions.

While the number of respondents with experiences from crowdsourcing solutions in their own organizations was relatively low, the different questions on policies and practices seem to reveal that the LAM institutions have not yet figured out, nor implemented and communicated, policies and expectations for whether or how they will handle user contributions. Both the rates of "I don't know" answers and the rate of what could be interpreted as laissez-faire policies indicate that policies on preserving user contributions are either lacking or not well communicated to the professionals. As such, user contributions appear more as a byproduct of online outreach and exposure rather than a method of enriching collections, accumulating material, or breaking out of the traditional views of users as literal "users" of LAMs, not active co-equals to the professionals. 


\section{Conclusions}

A key practical implication of the present study is that as it is still very rare to work with user contributions in a systematic manner, it would be important to gather more experiences and work with users, and develop ideas and approaches to engaging them in a mutually productive and useful manner. Similarly to how LAMs already for some time have been suffering from being socially useful but not necessarily used that much in practice (Usherwood et al. 2005), the current relevance of user contributions is still very much on the level of their potential social usefulness rather than in their demonstrated benefits in the LAM sector as a whole.

\section{References}

Bonacchi, C., A. Bevan, A. Keinan-Schoonbaert, D. Pett, and J. Wexler. "Participation in Heritage Crowdsourcing”. Museum Management and Curatorship, 34, no. 2, 166-182, 2019.

Eveleigh, A. "Crowding out the Archivist?: Locating Crowdsourcing Within the Broader Landscape of Participatory Archives". In Ridge, M. (ed.), Crowdsourcing our Cultural Heritage, pp. 211-230. London: Routledge, 2014.

Henningsen, E. and H. Larsen. "The Joys of Wiki Work: Craftsmanship, Flow and Selfexternalization in a Digital Environment”. In Audunson, R., H. Andresen, C. Fagerlid, E. Henningsen, H-C. Hobohm, H. Jochumsen, H. Larsen, and T. Vold (eds), Libraries, Archives and Museums as Democratic Spaces in a Digital Age. Berlin: De Gruyter Saur, 2020.

Huvila, I. "Navigators, Debaters or Information Architects? How Library, Museum and Archive Professionals Perceive their Role in the Future Society". In Riekert, W.-F. and I. Simon (eds), Information in e-Motion: Proceedings of the BOBCATSSS 2012 20th International Conference on Information Science Amsterdam, 23-25 January 2012, pp. 190-194, Bad Honnef, 2012. Bock + Herchen.

Huvila, I. "Archives, Libraries and Museums in the Contemporary Society: Perspectives of the Professionals”. In Kindling, M. and E. Greifeneder (eds), iConference 2014 Proceedings, pp. 45-64, Illinois, 2014. iSchools.

Huvila, I. "The Unbearable Lightness of Participating? Revisiting the Discourses of "Participation" in Archival Literature”. Journal of Documentation, 71, no. 2, 358-386, 2015.

Huvila, I. "Change and Stability in Archives, Libraries and Museums: Mapping Professional Experiences in Sweden”. Information Research, 21, no. 1, 2016.

Ivey, B. “Expressive Life and the Public Interest”. In Jones, S. (ed.), Expressive Lives, pp. 23-33. London: Demos, 2009.

Jansson, I.-M. "Organization of User-Generated Information in Image Collections and Impact of Rhetorical Mechanisms”. Knowledge Organization, 44, no. 7, 515-528, 2017.

Jansson, I.-M. “Negotiating Participatory KO in Crowdsourcing Infrastructures”. In Ribeiro, F. and M. E. Cerveira (eds), Challenges and Opportunities for Knowledge Organization in the Digital Age: Proceedings of the Fifteenth International ISKO Conference 9-11 July 2018 Porto, Portugal, pp. 863-870, Baden-Baden, 2018. Ergon-Verlag. 
Kalfatovic, M. R., E. Kapsalis, K. P. Spiess, A. V. Camp, and M. Edson. "Smithsonian Team Flickr: a Library, Archives, and Museums Collaboration in web 2.0 Space”. Archival Science, 8, no. 4, 267-277, 2008.

Marty, P. F. "Unintended Consequences: Unlimited Access, Invisible Work and the Future of the Information Profession in Cultural Heritage Organizations". Bulletin of the ASIS\&T, 38, no. 3, 27-31, 2012.

Nowotny, H., P. B. Scott, and M. T. Gibbons. Re-thinking Science: Knowledge and the Public in an Age of Uncertainty. John Wiley \& Sons, 2013.

Oomen, J. and L. Arroyo. Crowdsourcing in the Cultural Heritage Domain: Opportunities and Challenges. In Proceedings of the 5th International Conference on Communities and Technologies (138-149). Brisbane, Australia: ACM, 2011.

Owens, T. "Making Crowdsourcing Compatible with the Missions and Values of Cultural Heritage Organisations". In Ridge, M. (ed.), Crowdsourcing our Cultural Heritage, pp. 269280. London: Routledge, 2014.

Phillips, L. B. “The Role of Open Authority in a Collaborative Web”. In Ridge, M. (ed.), Crowdsourcing our Cultural Heritage, pp. 247-267. London: Routledge, 2014.

Ridge, M. (ed.). Crowdsourcing our Cultural Heritage. London: Routledge, 2016.

Roued-Cunliffe, H. and A. Copeland (eds). Participatory Heritage. London: Facet, 2016.

Theimer, K. Appraisal and Acquisition: Innovative Practices for Archives and Special Collections. Rowman \& Littlefield, 2015.

Usherwood, B., K. Wilson, and J. Bryson. "Relevant Repositories of Public Knowledge?: Libraries, Museums and Archives in 'the Information Age"”. Journal of Librarianship and Information Science, 37, no.2, 89-98, 2005.

Wilensky, H. L. “The Professionalization of Everyone?”. American Journal of Sociology, 70, no. 2, 137-158, 1964. 